\title{
Strength improvement of fibre cement product
}

\author{
Waranya Sonphuak* and Napassavong Rojanarowan
}

\begin{tabular}{|c|c|}
\hline CHRON I C LE & A B S T RACT \\
\hline $\begin{array}{l}\text { Article history: } \\
\text { Received February } 22013 \\
\text { Received in revised format } \\
\text { May } 282013 \\
\text { Accepted May } 302013 \\
\text { Available online } \\
\text { June } 62013 \\
\text { Keywords: } \\
\text { Six Sigma } \\
\text { Fibre cement } \\
\text { Strength } \\
\text { Modulus of Rupture (MOR) } \\
\text { Experimental Design }\end{array}$ & $\begin{array}{l}\text { This paper presents a methodology to improve the strength or the Modulus of Rupture (MOR) of } \\
\text { fibre cement. The Six Sigma approach with the DMAIC steps was applied to a case study } \\
\text { company. This research started from defining problem, setting the project objective and the } \\
\text { project scope. Next, the measurement system was analyzed and the process map was set up. The } \\
\text { potential factors of the problem was then determined. Due to there were many factors that affect } \\
\text { the MOR, the Cause and Effect Matrix and the Failure Mode and Effect Analysis technique were } \\
\text { then used to reduce the number of factors to be studied further. Next, three process factors, which } \\
\text { were the pulp slurry freeness, the film-layer thickness, and the pressure step, were optimized } \\
\text { using the results from the Box-Behnken experimental design. Other } 13 \text { remaining factors were } \\
\text { improved by creating or revising the standard work instructions and training the operators. After } \\
\text { that, the statistical process control and the control plan were set up to control the production } \\
\text { processes. After improvement, the process capability index (Ppk) significantly increased from } \\
0.26 \text { to } 1.35 \text {. }\end{array}$ \\
\hline
\end{tabular}

\section{Introduction}

Fibre cement is a construction material consisting of main raw materials including Portland cement, cellulose fibers and water. Fibre cement has been widely used for roof tile, wall, floor, and decorative applications. The most important property of fibre cement products is strength, which is measured in terms of modulus of rupture (MOR). Thus, there are many researches about parameters influencing MOR. For instance, Khorami and Ganjian (2011) studied on agricultural waste fibres of wheat and eucalytus and found that the type, the length, the diameter, and the texture of fibre affect the MOR. Moreover, the synthetic fiber such as polypropylene, polyvinyl alcohol, alkali-resistance glass fibres were added in the fibre cement product to improve the strength (Ikai et al., 2010; Alamshahi et al., 2012; Felekoglu et al., 2009). The additive or admixture such as silica fume, sepiolite, metakaolin were found that they can improve the properties if the optimal amount were added (Gutierrez et al., 2005; Aruntas et al., 2008; Kavas et al., 2004; Bezerra et al., 2006). Negro et al. (2005) presented that the flocculant, which was used for enhancing the overall efficiency of the machine, had a negative effect

* Corresponding author.

E-mail: Napassavong.O@chula.ac.th (N. Rojanarowan)

(C) 2013 Growing Science Ltd. All rights reserved.

doi: $10.5267 /$ j.ijiec.2013.06.004 
on the MOR property. Thus, the right selection of the flocculant was crucial in a production process. Moreover, the conditions and the parameters of manufacturing processes were also studied such as the curing condition, the slurry temperature, the felt speed, the line pressure, and the number of layers (MacVicar et al., 1999; Soroushian et al., 2012; Tonoli et al., 2010; Aruntas et al., 2008; Kus et al., 2006). From these researches, there were many factors affecting the MOR of the fibre cement product but there were a few researches that study covering all types of factors in real production processes such as factors related to man, machine, material, method, measurement and environment. Thus, the paper aims to demonstrate a systematic method named Six Sigma to prioritize, select, and improve the most important factors to improve the strength property.

\section{Process description}

The fibre cement production process is shown in Fig.1. First, pulp sheets are re-slushed in water until hydra-pulper becomes the pulp slurry. Additives, which are aluminium sulfate and silica fume are added for fiber mineralization purpose. The pulp slurry is sent to mix with cement and calcium carbonate in the final mixing process. The mixture is transferred to felt to be de-watered on the Flowon (laminating) process shown in Fig.2. The water in the mixture is removed by vacuum pumps and the mixture is formed by forming rollers and pressure rollers until it becomes a film layer at thickness about $0.40-0.70 \mathrm{~mm}$.

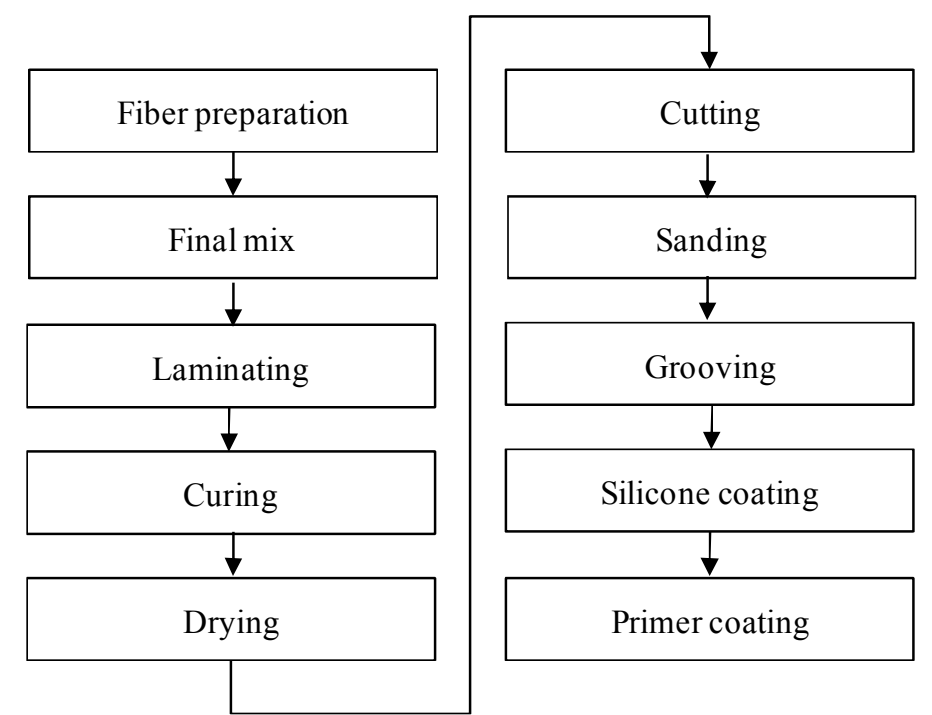

Fig.1. Production Processes of fibre cement product

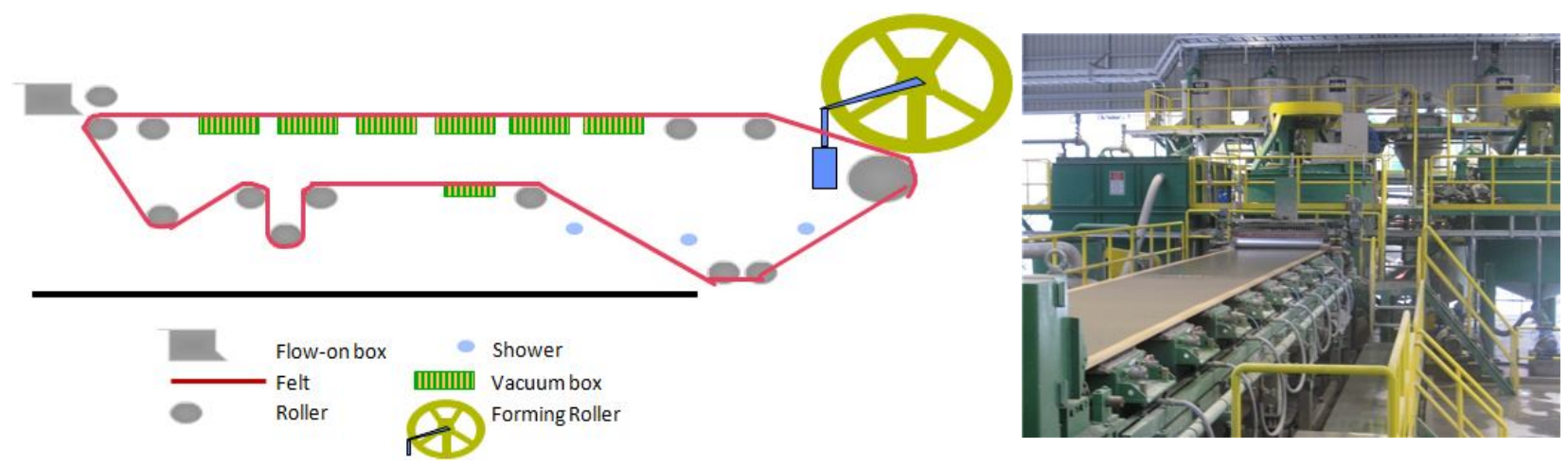

Fig. 2. Schematic view of the Flow-on process machine used for laminating of the fibre cement board 
The fibre cement boards are formed with the dimensions of 3,110 $\mathrm{mm}$. long, 1,280 $\mathrm{mm}$. wide and 11 $\mathrm{mm}$. thick. The boards are transferred to the primary curing chamber with $60-70^{\circ} \mathrm{C}, 95 \% \mathrm{RH}$ for 10 hours. Then, the boards from the primary curing chamber are sent to the secondary curing chamber at the ambient temperature and 95\% RH for 6 days and are dried in a dryer section for 10 hours. After these processes, the boards are texturized by a sanding process to produce grain surface like real wood texture. Then, the boards are cut into pieces, grooved to a make pattern on each piece and coated with silicone and primer to protect the finished products from moisture.

The scope of this study is to investigate the effects of process parameters on the MOR of fibre cement board since the fiber preparation to the curing process.

\section{Methodology}

Since this research aims to study all types of factors affecting the strength of the fibre cement and improve the significant factors, thus a systematic method needs to be utilized in order to prioritize, select, and improve the most important factors. The Six Sigma approach was implemented in this study since it is a systematic approach and has been widely used for improving product quality and reduce variation of processes (Sahoo et al., 2008; Aksoy \& Orbak, 2009; Sokovic et al., 2006). The Six Sigma approach consists of the DMAIC steps, which are Define, Measure, Analyze, Improve, and Control. This paper implemented the DMAIC steps and the tools of Six Sigma approach as shown in Table 1. In the Define phase, project charter and process map were written to describe the problem and current process. In the Measure phase, the measurement system and the process capability were analyzed to make sure that the current performance of the process is correctly understood. In the Analyze phase, the key process input variables (KPIVs) were indentified and reduced to be investigated further in the next phase using the Cause-and-Effect Matrix and the criteria from the Failure Mode and Effects Analysis. In the Improve phase, the design of experiment technique was used to test for the significance of the selected factors and to determine the optimal levels of the significant factors. In the Control phase, a control plan and other control tools, which were control charts and check list were set up to maintain the performance after improvement (Pyzdek , 2003).

Table 1

The DMAIC steps of Six Sigma approach

\begin{tabular}{|c|c|c|}
\hline Phase & Purposes & Tools \\
\hline Define phase & $\begin{array}{l}\text { - The project team clarifies the problem, the objective and } \\
\text { the scope of the project. } \\
\text { - Document the processes }\end{array}$ & $\begin{array}{ll}- & \text { Project charter } \\
\text { - } & \text { Process Map }\end{array}$ \\
\hline Measure phase & $\begin{array}{ll}\text { - } & \text { Evaluate measurement system } \\
\text { - } & \text { Analyze process capability }\end{array}$ & $\begin{array}{ll}\text { - } & \text { MSA } \\
\text { - } & \text { Process Capability Analysis }\end{array}$ \\
\hline Analyze phase & - Identify and reduce the number of KPIVs & $\begin{array}{ll}\text { - } & \text { C\&E Matrix } \\
\text { - } & \text { FMEA }\end{array}$ \\
\hline Improve phase & - Design of experiment to optimize KPIVs & $\begin{array}{l}\text { - Design of experiment: Box- } \\
\text { Behnken design }\end{array}$ \\
\hline Control phase & $\begin{array}{l}\text { - } \quad \text { Verify long term capability } \\
\text { - Implement control plan } \\
\text { - Training }\end{array}$ & $\begin{array}{ll}\text { - } & \text { Control plan } \\
\text { - } & \text { I-MR Chart } \\
\text { - } & \text { Check list }\end{array}$ \\
\hline
\end{tabular}

\section{Results}

The results in each of the DMAIC steps are explained in the following sections. 


\subsection{Define phase}

In the Define phase, the project charter was written as a communication tool for the improvement team to understand the problem and the project objectives. The project charter as shown in Table 2 consisted of the main elements, which are problem statement, objective statement, project scope, project metrics, project constraints and assumptions. After analyzing the defect data, it was found that the major quality problem was that the product was brittle or having low MOR leading to unreached targets of the case study company including

1) The scrap amount of $3.25 \%$ of output exceeded the maximum limit of $3.00 \%$.

2) The customer claim value from product cracking per net sale of $0.38 \%$ exceeded the maximum limit of $0.25 \%$.

3) The MOR long-term process capability index (Ppk) of 0.26 was less than the standard acceptable value of 1.33 .

\section{Table 2}

Project charter

\begin{tabular}{|c|c|}
\hline Project title: & Strength improvement of fibre cement product \\
\hline Business case: & $\begin{array}{l}\text { The brittle or low MOR product causes a significant scrap cost and a customer claim value } \\
\text { per net sale exceed the maximum limit of the company. }\end{array}$ \\
\hline Problem statement: & $\begin{array}{l}\text { The brittle or low MOR product causes a scrap cost of } 3.25 \% \text { of output and a customer } \\
\text { claim value per net sale of } 0.38 \% \text {, which exceed the company maximum limits of } 3 \% \text { and } \\
0.25 \% \text { respectively. The Ppk of the MOR of fibre cement products during January - June, } \\
2012 \text { of } 0.26 \text { was significantly less than the standard acceptable value of } 1.33 \text {. This leads to } \\
\text { the scrap cost of brittle products on average of } 378,162 \mathrm{THB} / \text { month. }\end{array}$ \\
\hline Objective statement: & $\begin{array}{l}\text { Increase the Ppk of the MOR to be higher than } 1.33 \text { for board thickness of } 11 \mathrm{~mm} \text {. by } \\
\text { February } 28,2013 \text {. }\end{array}$ \\
\hline Project scope: & $\begin{array}{l}\text { Study parameters affecting the MOR of the board of thickness } 11 \mathrm{~mm} \text {. from the fiber } \\
\text { preparation until the curing process. }\end{array}$ \\
\hline Project metrics: & $\begin{array}{l}\text { - } \text { Business metric: Scrap cost and customer claim value } \\
\text { - } \quad \text { Primary metric: Ppk of MOR } \\
\text { - } \text { Secondary metric: Area to store scrapped products } \\
\text { - } \quad \text { Financial metric: Scrap cost and customer claim value }\end{array}$ \\
\hline Project assumption: & Team has authority to do experiments and implement solutions. \\
\hline Project constraint: & Team meeting three hours every Thursday \\
\hline Team members: & $\begin{array}{l}\text { - } \text { Vice President: Manufacturing \& Quality Management Function } \\
\text { - } \quad \text { Plant Manager } \\
\text { - } \quad \text { Quality Assurance Section Manager } \\
\text { - } \quad \text { Quality Control Engineer }\end{array}$ \\
\hline
\end{tabular}

\subsection{Measure phase}

The aim of the measure phase is to investigate the existing system. Before analyzing the collected data, the measurement system has to be investigated first to ensure that the measurements are reliable. The measurements were tested using the Universal Testing Machine, model: Lloyd EZ20. Next, the gage repeatability and reproducibility analysis (GR\&R) was applied for the MOR tested data to check whether the precision of the measurement system was reliable. The data was collected by sampling boards of thickness $11 \mathrm{~mm}$. from the production process at various time and tested by two operators 
with three replicates. Since test was destructive, thus a nested GR\&R analysis was performed on the tested data. The result of the GR\&R analysis was presented in Table 3.

Table 3

GageR\&R results of MOR tested data

\begin{tabular}{lcccc}
\hline \multicolumn{1}{c}{ Source } & $\begin{array}{c}\text { StdDev } \\
(\mathrm{SD})\end{array}$ & $\begin{array}{c}\text { Study Variance } \\
(6 * \mathrm{SD})\end{array}$ & $\begin{array}{c}\text { \%Study Variance } \\
(\% \mathrm{SV})\end{array}$ & $\begin{array}{c}\text { \%Tolerance } \\
(\mathrm{SV} / \text { Toler })\end{array}$ \\
\hline Total Gage R\&R & 0.10880 & 0.65281 & 10.12 & 15.73 \\
Repeatability & 0.10880 & 0.65281 & 10.12 & 15.73 \\
Reproducibility & 0.00000 & 0.00000 & 0.00 & 0.00 \\
Part-To-Part & 1.06981 & 6.41883 & 99.49 & 154.65 \\
\hline Total Variation & 1.07532 & 6.45194 & 100.00 & 155.44 \\
\hline
\end{tabular}

The precision to tolerance $(\mathrm{P} / \mathrm{T})$ ratio and the percentage of the measurement variation to the total variability $(\mathrm{P} / \mathrm{TV})$ were $15.73 \%$ and $10.12 \%$, respectively. Since they were less than the acceptable value of $30 \%$ (AIAG, 2002), thus the team accepted the precision of the measurement system.

Next, the long-term process capability of the MOR of the boards of thickness $11 \mathrm{~mm}$. was studied to understand the distribution of the MOR of the product. The boards, which have the MOR of less than 14.00 Mpa., are regarded as defectives. Fig. 3 showed that before improvement, the MOR was at the mean of $15.108 \mathrm{Mpa}$. and the overall standard deviation of $1.438 \mathrm{Mpa}$., resulting in the defective proportion of 220,495 PPM and the long-term process capability (Ppk) of 0.26, which was unacceptable (AIAG, 2002). In addition, the process was not stable as can be seen from the control charts. The process capability index (Ppk) was calculated as a process capability measure using Eq. 1.

$P_{p k}=\frac{\mu-L S L}{3 \sigma_{L T}}$

where: $\quad \mu \quad=$ the process mean

$\mathrm{LSL}=$ the lower specification limit

$\sigma_{L T}=$ the long-term or overall standard deviation

Since the process capability was unacceptable, the mean MOR should be increased and the overall variation of MOR should be reduced.

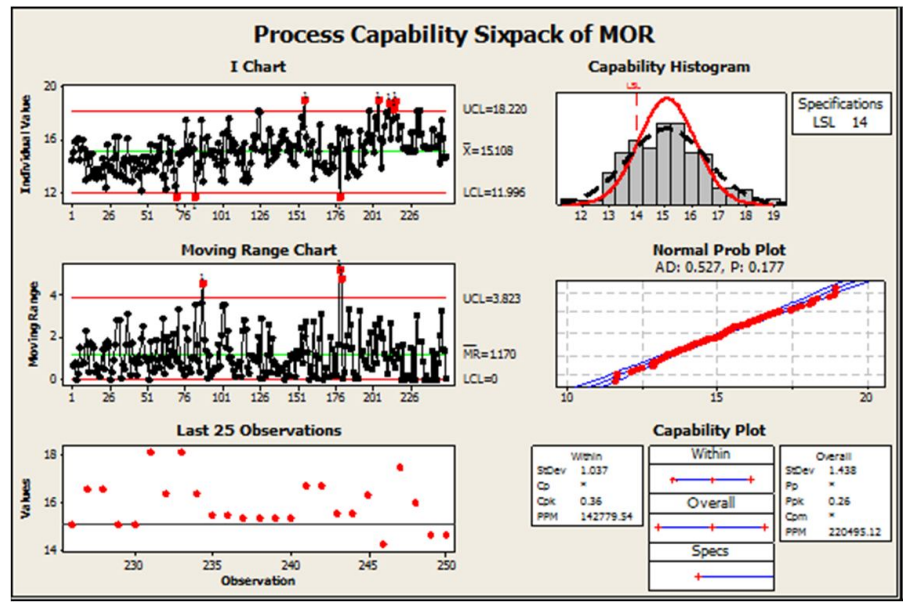

Fig.3. Process capability of MOR before improvement 
In this phase, the parameters which affected the MOR were identified and prioritized. The team listed out 39 parameters from the fiber preparation process to the curing process related to man, machine, material, measurement, and environment (5M 1E analysis). The rating in the cause and effect matrix was then applied to scope down to important factors. After rating scores, all scores of each member were summed and prioritized by the Pareto chart. In this step, the number of parameters was reduced from 39 to 16. Next, the criteria from the failure mode and effects analysis (FMEA), which were the severity rating, the occurrence rating, and the detection rating (AIAG, 2001), were applied to screen for more important factors based on the Risk Priority Numbers (RPNs) (Su \& Chou, 2008). The RPNs were determined by the multiplication of the severity rating, the occurrence rating, and the detection rating. After the FMEA analysis, 16 factors were selected to be analyzed further. These 16 factors were categorized into three groups according to next improvement methods as follows and shown in Table 4.

- Group I: The factors were improved by finding the optimal factor setting using the Design of Experiment (DOE) technique.

- Group II: The factors were improved by reviewing or creating work instruction.

- Group III: The factors were improved by training of the operators.

Table 4

Description of selected factors

\begin{tabular}{|c|c|c|c|}
\hline NO. & Type & Factors & Improvement method \\
\hline \multicolumn{4}{|c|}{ Group I: } \\
\hline 1 & Material & Freeness of pulp slurry & Design of Experiment \\
\hline 2 & Machine & Film thickness & Design of Experiment \\
\hline 3 & Machine & Pressure step & Design of Experiment \\
\hline \multicolumn{4}{|c|}{ Group II: } \\
\hline 1 & Material & Variation of DLK quality & Categorize DLK by freeness value and \\
\hline 2 & Method & Improper fiber preparation recipe & Create the standard recipe adjustment \\
\hline 3 & Material & Pulp slurry recipe was adjusted incorrectly during & Create work instruction. \\
\hline 4 & Material & Variation of freeness from pulp weighting & Create work instruction. \\
\hline 5 & Measurement & Improper sampling method of fiber slurry & Review work instruction. \\
\hline 6 & Measurement & Improper sampling method of final mixture & Review work instruction. \\
\hline 7 & Measurement & Operators in quality control section sampled pulp slurry & Create work instruction. \\
\hline 8 & Material & Variation of pulp slurry & Create work instruction. \\
\hline 9 & Material & Consistency of pulp slurry was adjusted improperly in the & Create work instruction. \\
\hline 10 & Material & Consistency of pulp slurry was adjusted improperly in the & Create work instruction. \\
\hline \multicolumn{4}{|c|}{ Group III: } \\
\hline 1 & Man & Operators in fiber preparation section did not understand & Training the operators. \\
\hline 2 & Man & Operators in final mix section did not understand the & Training the operators. \\
\hline 3 & Man & Operators in Lamination section did not understand the & Training the operators. \\
\hline
\end{tabular}

\subsection{Improve phase}

The factors in Group II and III were improved by reviewing or creating work instructions. Regarding the factors in Group I, which were the freeness of pulp slurry, the film-layer thickness, and the pressure step, the effects of these process factors on the MOR were studied further using the design of experiment (DOE) technique. An experiment was carried out to test whether these factors statistically affected the MOR and to find the optimal setting of these parameters. The Canadian Standard Freeness (CSF) is a standard measure of the drainage properties of pulp suspensions, which related to the initial drainage rate of the wet pulp pad during the de-watering process. It is usually applicable to the prediction of the strength properties of mechanical pulps and correlates well with the amount of fines in the pulp, which affect product properties. The film-layer thickness factor refers to the thickness of film layers after the moisture is removed. The pressure step refers to the pressure between forming rollers and pressure rollers that affect the density of the board. 


\subsubsection{Design of Experiment}

In this study, the Box-Behnken experimental design was chosen for finding out the relationship between the response (MOR) and the process factors (freeness, film-layer thickness and pressure step). The Box-Behnken design is formed by combining $2^{\mathrm{k}}$ factorial runs with incomplete block design. The resulting designs are usually very efficient in terms of the number of required runs, and there are either rotatable or nearly rotatable (Montgomery, 2012). The design consists of the center points and the middle points of the edges and requires an experiment number according to $\mathrm{N}=\mathrm{k}^{2}+\mathrm{k}+\mathrm{cp}$, where $(\mathrm{k})$ is the factor number and (cp) is the replicate number of the center points. For the three-level threefactor Box-Behnken design, a total of 15 experimental runs were needed. The experimental factors and their levels are shown in Table 5.

Table 5

Experimental factors and their levels

\begin{tabular}{cccccc}
\hline \multirow{2}{*}{ Symbol } & \multirow{2}{*}{ Factors } & \multirow{2}{*}{ Unit } & \multicolumn{3}{c}{ Levels of Factors } \\
\cline { 3 - 6 } & & & Low & Center & High \\
\hline A & Freeness & ml.CSF & 430 & 480 & 530 \\
B & Film-layer thickness & mm. & 0.45 & 0.55 & 0.65 \\
C & Step pressure & bar & 1.2 & 1.4 & 1.6 \\
\hline
\end{tabular}

\subsubsection{Experiment setup}

The experiment began with the fiber preparation process, where the freeness of pulp slurry (factor A) was set. In this process, the pulp sheets were re-slushed in hydra-pulper in water. Then, the pulp slurry was sampled to test freeness and was transferred to mix with cement and calcium carbonate in the final mix process. Then, the mixture flowed on the felt and the water was removed. Then, the film layers were laminated with the forming rollers and the pressure rollers to obtain fibre cement boards. In this process, the film thickness (factor B) and the pressure step (factor C) were set. The film layers (thickness of 0.45-0.65 mm./layer) were stacked until reaching the thickness of $11 \mathrm{~mm}$. as boards. Then, the boards were transferred to the primary curing process for 10 hours, the secondary curing for 6 days, and dried at the dryer for 10 hours. After that, the boards were sampled and cut as specimens. Then, they were tested by the Universal Testing Machine to obtain the MOR values. The testing process was shown in Fig. 4.

\subsubsection{Analysis of experimental results}

The analysis of variance (ANOVA) was carried out to test whether the three factors were statistically significant to the MOR at the significance level of $5 \%(\alpha=0.05)$. The ANOVA results showed that the quadratic regression model is significant.

\section{Table 6}

ANOVA results of the MOR.

\begin{tabular}{lcrrrr}
\hline Source & DF & Sum of Square & Mean Square & F & P - Value \\
\hline Freeness (A) & 1 & 4.1041 & 4.1041 & 25.04 & 0.004 \\
Film layer thickness (B) & 1 & 0.2888 & 0.2888 & 1.76 & 0.242 \\
Pressure step (C) & 1 & 0.6903 & 0.6903 & 4.21 & 0.095 \\
Freeness*Freeness (AA) & 1 & 3.3377 & 3.6188 & 22.08 & 0.005 \\
Film-layer thickness* Film-layer thickness (BB) & 1 & 0.0062 & 0.0251 & 0.15 & 0.711 \\
Pressure step*Pressure step (CC) & 1 & 1.0767 & 1.0767 & 6.57 & 0.050 \\
Freeness* Film-layer thickness (AB) & 1 & 0.0756 & 0.0756 & 0.46 & 0.527 \\
Freeness*Pressure step (AC) & 1 & 0.0001 & 0.0001 & 0.00 & 0.981 \\
Film-layer thickness*Pressure step (BC) & 1 & 0.2652 & 0.2652 & 1.62 & 0.259 \\
Residual Error & 5 & 0.8194 & 0.1639 & \\
Lack-of-Fit & 3 & 0.7648 & 0.2549 & 9.34 & 0.098 \\
\hline Total & 14 & 10.6642 & & & \\
\hline
\end{tabular}




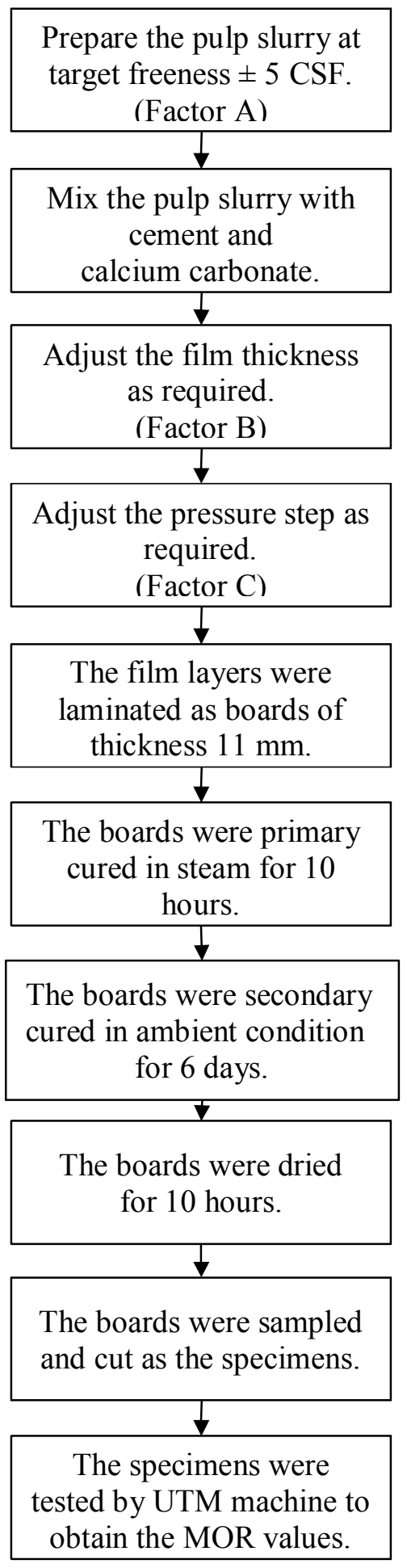

Fig. 4. Process flow of testing.

\subsubsection{Response Surface Model}

The backward elimination regression technique was then used to find the equation of the relationship between the MOR and the significant experimental factors. The response surface model was shown in Eq. 2.

$\mathrm{Y}_{\mathrm{MOR}}=139.3-0.392 \mathrm{X}_{\mathrm{A}}-36 \mathrm{X}_{\mathrm{C}}+0.00039 \mathrm{X}_{\mathrm{A}}^{2}+13.3 \mathrm{X}_{\mathrm{C}}^{2}$ 
where:

$\mathrm{Y}_{\mathrm{MOR}}=\quad$ Modulus of Rupture (MOR)

$\mathrm{X}_{\mathrm{A}}=$ Freeness of pulp slurry

$\mathrm{X}_{\mathrm{B}} \quad=\quad$ Film thickness

$\mathrm{X}_{\mathrm{C}}=$ Pressure step

Eq. 2 showed that the pulp slurry freeness $\left(\mathrm{X}_{\mathrm{A}}\right)$ and the pressure step $\left(\mathrm{X}_{\mathrm{C}}\right)$ were significant factors in terms of their main effects and their second-order polynomial effects. The model adequacy was confirmed by the satisfactory value of $86.18 \% \mathrm{R}^{2}$ and $80.65 \% \mathrm{R}_{\text {(adj.). }}^{2}$

\subsubsection{Optimization of process factors}

The optimum setting of the pulp slurry freeness and the pressure step was determined using the optimization technique based on the relationship model shown in Eq. 2. The optimization result shown in Fig. 5 showed that it was predicted that the maximum MOR of $20.54 \mathrm{Mpa}$. could be obtained by setting the pulp slurry freeness at $430 \mathrm{~mL}$. CSF and the pressure step at 1.6 bar. Since the regression model indicated that the film-layer thickness was not significant which correspond with the finding from Kus et al. (2012) that the number of layers (film-layer thickness) has less effect than the line pressure effect. Therefore, the film-layer thickness was selected at $0.65 \mathrm{~mm}$. to yield the highest production capacity.

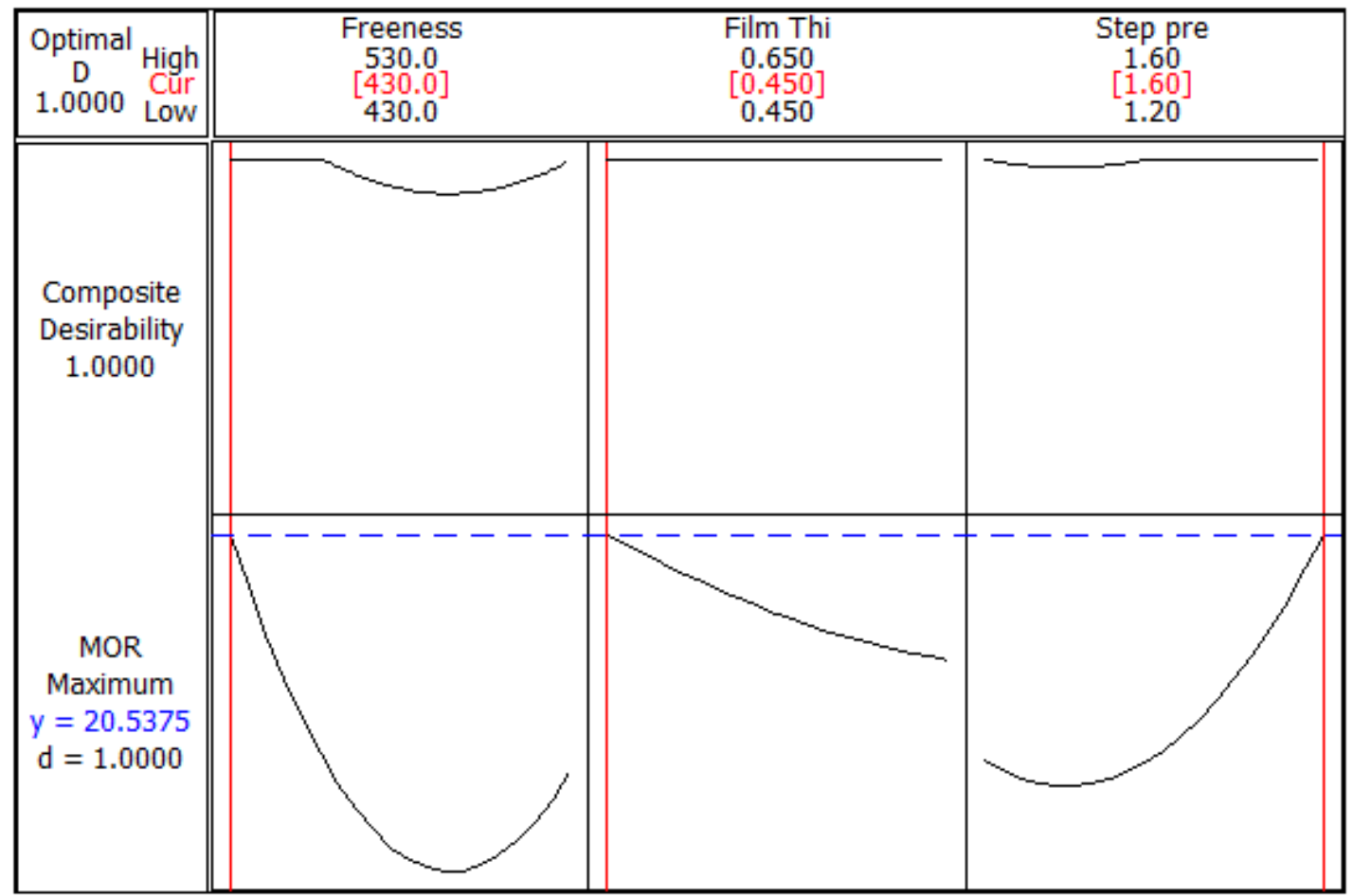

Fig. 5. The optimization results

\subsection{Control phase}

In the Control phase, the improvement result at the optimum setting was confirmed with the confirmatory experiment. The result was shown in Fig. 6. The process capability (Ppk) of the MOR increased from 0.26 (before improvement) to 1.35 (after improvement). The Ppk after improvement was acceptable since it was greater than the standard acceptable value of 1.33. The comparative results of process capability before and after improvement were shown in Table 7 . It can be seen that the mean 
of MOR after improvement was significantly increased and the variation of the MOR among boards was significantly decreased.

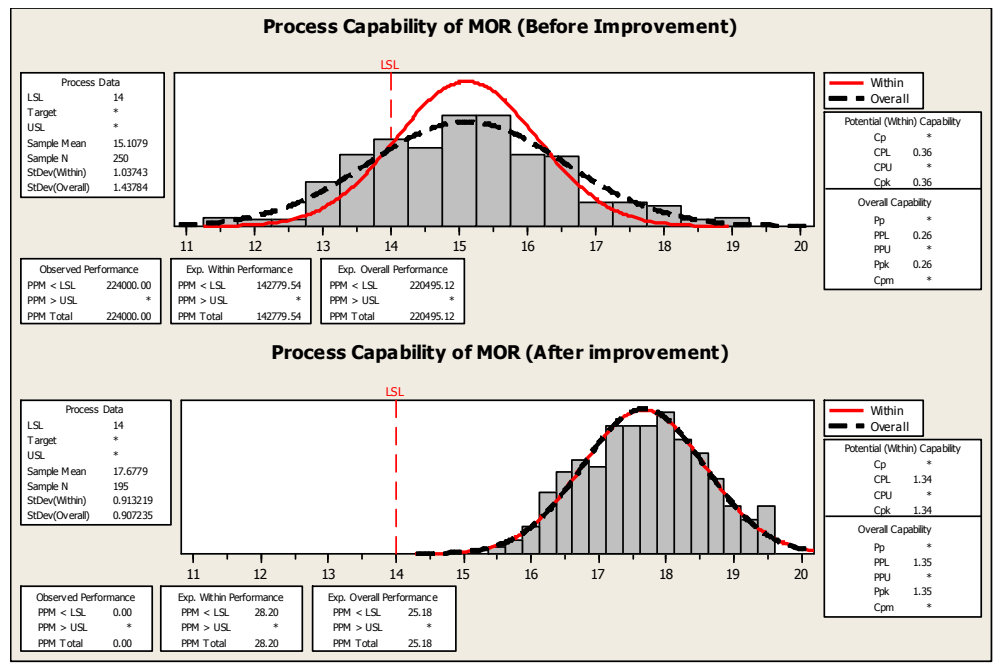

Fig. 6. Comparative process capability plots of the MOR before and after improvement.

\section{Table 7}

Comparative results of process capability before and after improvement

\begin{tabular}{lcc}
\hline & Before improvement & After improvement \\
\hline Mean & $15.11 \mathrm{Mpa}$. & $17.68 \mathrm{Mpa}$. \\
Overall standard deviation & $1.44 \mathrm{Mpa}$ & $0.91 \mathrm{Mpa}$. \\
Overall long-term capability index (Ppk) & 0.26 & 1.35 \\
\hline
\end{tabular}

To sustain the Ppk of the MOR after improvement, the control plan was developed to ensure that processes and products were consistent. The control plan of the process factors was shown in Table 8 . The freeness was controlled using the I-MR control charts. The film thickness and the pressure step were monitored with the check sheets every two hours. Regarding the MOR of the produced boards, the Quality Control section will sample the fibre cement boards after the drying process every 4 hours to test the MOR property and monitor the MOR by using the I-MR chart, which was shown in Fig. 7. The control charts showed that the process after improvement was in-control.

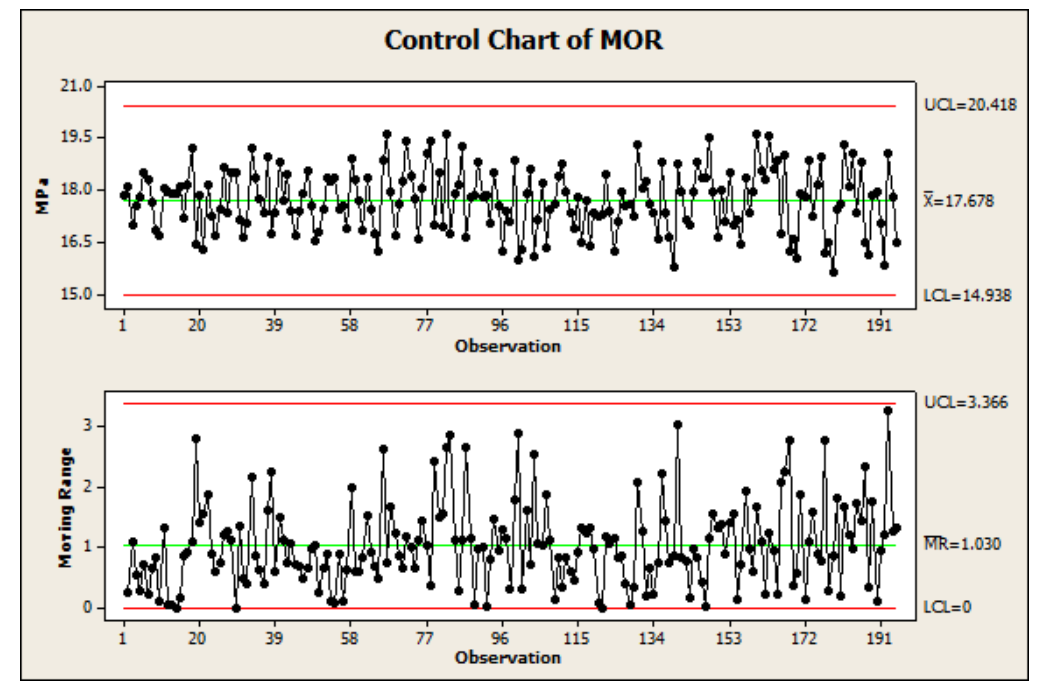

Fig. 7. I-MR control charts of MOR 
Table 8

Control plan

\begin{tabular}{|c|c|c|c|c|c|c|c|}
\hline \multirow{2}{*}{ Process } & \multirow{2}{*}{ Control Point } & \multirow{2}{*}{ Setting } & \multirow{2}{*}{ Unit } & \multicolumn{2}{|c|}{ Control } & \multirow{2}{*}{ Responsible Persons } & \multirow{2}{*}{ Action plan } \\
\hline & & & & Tools & Frequency & & \\
\hline Fiber preparation & Freeness & $430 \pm 5$ & ml.CSF & I-MR Chart & Every 2 hours & $\begin{array}{c}\text { - Fiber preparation operators } \\
\text { - QC Analysts }\end{array}$ & $\begin{array}{l}\text { - Inform supervisor to adjus } \\
\text { pulp ratio. }\end{array}$ \\
\hline Lamination & Film thickness & 0.65 & $\mathrm{~mm}$ & Check sheet & Every 2 hours & - Lamination operators & $\begin{array}{l}\text { - Inform supervisor to adjus } \\
\text { machine setting. }\end{array}$ \\
\hline Lamination & Step Pressure & 1.6 & bar & Check sheet & Every 2 hours & - Lamination operators & $\begin{array}{l}\text { - Inform supervisor to adjus } \\
\text { machine setting. }\end{array}$ \\
\hline
\end{tabular}

\section{Conclusion}

This paper presents the methodology to improve the strength or the Modulus of Rupture (MOR) of the fibre cement. The Six Sigma approach with the DMAIC steps was applied to a case study company. In the Define phase, the problem found was that the brittle or low MOR product causes a scrap cost of $3.25 \%$ of output and a customer claim value per net sale of $0.38 \%$, which exceed the company maximum limits of $3 \%$ and $0.25 \%$ respectively. The Ppk of the MOR of the fibre cement products during January - June, 2012 of 0.26 was significantly less than the standard acceptable value of 1.33. This leads to the scrap cost of brittle products on average of $378,162 \mathrm{THB} /$ month. Thus, this research has the objective to increase the Ppk of the MOR to be higher than 1.33 for board thickness of $11 \mathrm{~mm}$. by February 28, 2013.

In the Measure phase, the precision of the measurement system was evaluated using the nested gage repeatability and reproducibility (GR\&R) technique and was found that the precision of the measurement system was acceptable. Therefore, the collected process capability data was reliable to show the process capability index (Ppk) of the MOR is 0.26 .

In the Analyze phase, the potential factors of the problem were then identified. Due to there were many factors that affect the MOR, the Cause and Effect Matrix and the Failure Mode and Effects Analysis technique were then used to reduce the number of factors from 39 to 16 to be studied further. These 16 factors were classified into three groups based on the next improvement methods.

In the Improve phase, factors in Group I, which were the pulp slurry freeness, the film-layer thickness, and the pressure step were optimized based on the relationship equation obtained from the BoxBehnken experimental design. It was found that the optimal factor levels of these factors to reach the maximum MOR were at the pulp slurry freeness of $430 \mathrm{~mL}$. CSF and the pressure step of $1.6 \mathrm{bar}$. Since the film-layer thickness was not statistically significant, thus it was set at $0.65 \mathrm{~mm}$. to yield the highest production capacity. Ten factors in Group II were related to no or unclear work instructions. Therefore, some work standards were created or revised. Group III were factors about operators did not understand the machine setting. Thus, the training of these operators was performed.

In the Control phase, the statistical process control and the control plan were set up to control the production processes. After improvement, the process capability index (Ppk) significantly increased from 0.26 to 1.35 .

\section{References}

Aksoy, B., \& Orbak, A.Y. (2009). Reducing the quantity of reworked parts in a robotic arc welding process. Quality and Reliability Engineering International, 25, 495-512.

Alamshahi, V., Taeb, A., Ghaffarzadeh, R., \& Rezaee, M.A. (2012). Effect of composition and length of PP and polyester fibres on mechanical properties of cement based composites. Construction and Building Materials, 36, 534-537. 
Aruntas, H.Y., Cemalgil, S., Simsek, O., Durmus, G., \& Erdal, M. (2008). Effects of super plasticizer and curing conditions on properties of concrete with and without fiber. Materials Letters, 62, 34413443.

Automotive Industry Action Group (AIAG). (2002). Measurement Analysis (MSA). $3^{\text {rd }}$ ed. Michigan, USA.

Automotive Industry Action Group (AIAG). (2001). Potential Failure Mode and Effects Analysis. $3^{\text {rd }}$ ed. Michigan, USA.

Bezerra, E.M., Joaquim, A.P., Savastano Jr. H., John, V.M., \& Agopyan, V. (2006). The effect of different mineral additions and synthetic fiber contents on properties of cement based composites. Cement and Concrete Composites, 28, 555-563.

Felekoglu, B., Tosan, K., \& Baradan, B. (2009). Effects of fibre type and matrix structure on the mechanical performance of self-compacting micro-concrete composites. Cement and Concrete Research, 39, 1023-1032.

Gutierrez, R.M., Diaz, L.N., \& Delvasto, S. (2005). Effect of pozzolans on the performance of fiberreinforced mortars. Cement and Concrete Composites, 27, 593-598.

Ikai, S., Reichert, J.R., Rodrigues, A.V., \& Zampieri, V.A. (2009). Asbestos-free technology with new high toughness polypropylene (PP) fibres in air-cured Hatscheck process. Construction and Building Materials, 24, 171-180.

Kavas, T., Sabah, E., \& Celik, M.S. (2004). Structural properties of sepiolite-reinforced cement composite. Cement and Concrete Research, 34, 2135-2139.

Khorami, M., \& Ganjian, E. (2011). Comparing flexural behavior of fibre-cement composites reinforced bagasse:Wheat and eucalyptus. Construction and Building Materials, 25, 3661-3667.

Kus, H., Ozgur, E., \& John, V.M. (2006). Effects of process parameters on physical and mechanical properties of fiber-cement sheets. Inorganic Bonded Fiber Composites Conference.

MacVicar, R., Matuana, L.M., \& Balatinecz, J.J. (1999). Aging mechanisms in cellulose fiber reinforced cement composites. Cement and Concrete Composites, 21, 189-196.

Montgomery, D.C. (2012). Design and analysis of experiments. John Wiley \& Sons.

Negro, C., Sanchez, L.M., Fuente, H., \& Blanco, A. (2005). Effects of flocculants and sizing agents on bending strength of fiber cement composites. Cement and Concrete Research, 35, 2104-2109.

Pyzdek, T. (2003). The Six Sigma handbook revised and expanded. McGraw-Hill.

Sahoo, A.K., Tiwari, M.K., \& Mileham, A.R. (2007). Six Sigma based approach to optimize radial forging operation variables. Journal of Materials Processing Technology, 202, 125-136.

Sokovic, M., Pavletic, D., \& Krulcic, E. (2006). Six Sigma process improvements in automotive parts production. Journal of Achievements in Materials and Manufacturing Engineering, 19, 96-102.

Soroushian, P., Won, J.P., \& Hassen, M. (2012). Durability characteristics of $\mathrm{CO}_{2}$-cured fiber reinforced cement composites. Construction and Building Materials, 34, 44-53.

$\mathrm{Su}$, C.T., \& Chou, C.J. (2008). A systematic methodology for the creation of Six Sigma projects: A case study of semiconductor foundry. Expert Systems with Applications, 34, 2693-2703.

Tonoli, G.H.D., Santos, S.F., Joaquim, A.P., \& Savastano Jr. H. (2010). Effect of accelerated carbonation on cementitious roofing tiles reinforced with lignocellulosic fibre. Construction and Building Materials, 24, 193-201. 